\title{
Role of misoprostol 4 hourly versus 6 hourly in medical termination of pregnancy in $2^{\text {nd }}$ trimester.
}

\footnotetext{
1. MBBS, FCPS

Senior Registrar (O \& G) Jinnah Medical and Dental College Karachi.

2. MBBS, FCPS

Associate Professor (O \& G) Jinnah Medical and Dental College Karachi.

3. MBBS, FCPS

Consultant Gynecologist (O \& G) Jinnah Medical and Dental College Karachi.

4. MBBS, FCPS

Senior Registrar (O \& G) Jinnah Medical and Dental College Karachi.

5. MBBS, FCPS

Consultant Gynecologist (O \& G)

Jinnah Medical and Dental College Karachi.

6. MBBS, FCPS

Registrar (O \& G)

Jinnah Medical and Dental College Karachi.
}

Correspondence Address:

Dr. Shazia Aftab

Department (O \& G)

Jinnah Medical and Dental College

Karachi.

drshaziaaftab@gmail.com

Article received on:

21/12/2020

Accepted for publication:

25/02/2021

\section{Komal Devi ${ }^{1}$, Shazia Aftab², Reena ${ }^{3}$, Huma Baloch ${ }^{4}$, Devi Kumari ${ }^{5}$, Samina Ayaz}

ABSTRACT... Objective: To determine efficacy of misoprostol given in 4 hourly versus 6 hourly intervals in second trimester for termination of pregnancy. Study Design: Cross sectional study. Setting: Study was conducted at the department of Obstetrics and Gynecology of Jinnah Medical and Dental College Karachi. Period: March to August 2020. Material \& Methods: Pregnant ladies in second trimester, requiring abortion due to medical reasons, were planned for termination of pregnancy. Two groups were made. Patients in Group-A were given misoprostol 4 hourly and those in Group-B were given misoprostol 6 hourly. Similar dose of drug (200ug) was given in both groups and monitoring was done. If abortion done in 48 hours, it was considered effective abortion and if not happened in 48 hours, it was considered a failed abortion. Consent was taken from all ladies in study group. Ethical approval was taken from ethical review committee. Results: Total 140 cases were studied, 70 cases in each group, A \& B. Age range of cases was 16-40 years with mean age of $26.4 \pm 3.5$ years. Most of the cases were having age between 2030 years $(63.5 \%)$. Group- $\mathrm{A}(\mathrm{N}=70)$ was given misoprostol 4 hourly, where abortion was done in $94.3 \%$ cases while abortion failed in 5.7\% cases. In Group-B ( $N=70)$ misoprostol was given 6 hourly, induced abortion in $82.8 \%$ and failed in $17.1 \%$ cases. Conclusion: Misoprostol dose of 20 ug given via vaginal route is much effective drug for medical termination of pregnancy when given 4 hourly instead 6 hourly, with low failure rate.

Key words: $\quad$ Abortion, Misoprostol, Second Trimester, Termination of Pregnancy.

Article Citation: Devi K, Aftab S, Reena, Baloch H, Kumari D, Ayaz S. Role of misoprostol 4 hourly versus 6 hourly in medical termination of pregnancy in 2nd trimester. Professional Med J 2021; 28(11):1645-1649.

https://doi.org/10.29309/TPMJ/2021.28.11.6285

\section{INTRODUCTION}

All over the world annually $20 \%$ pregnancies end up in abortions. ${ }^{1}$ Planned abortions are very common globally. Causes may be will of the parents, unintentional pregnancy or medically indicated. In our country abortions are carried out in government hospitals only when it is medically required and it is harmful to mother health. ${ }^{2}$ Misoprostol has been approved by FDA for the treatment of gastric ulcers taken orally. Due to its uterotonic and cervical ripening actions it is also used for medical termination of pregnancies. It is used for evacuation of uterus in case of fetal death and also used for induction of labor. It can be used to treat or prevent post-partum hemorrhage. Most of the time medical termination of pregnancy (TOP) is done in first trimester while in $5-15 \%$ cases in second trimester. ${ }^{3}$ In our study TOP is related to second trimester of pregnancy. There are surgical and medical methods for abortions. But here we are concerned with only medical method. Prostaglandins are commonly used for TOP, while other drugs are also available for this purpose. ${ }^{4}$ Intra amniotic hypertonic saline injection causes heart failure and fetal death. Uterine evacuation and curettage is associated with infection and uterine perforation. Misoprostol is a synthetic E1 prostaglandin and induce uterine contraction and cervical changes. ${ }^{5}$ It is commonly used in second trimester for TOP. When misoprostol was not introduced, prostaglandins E2 and F2 alpha were usually used for medical TOP in $2^{\text {nd }}$ trimester. Prostaglandins E2 and F2 alpha are costly, used in high doses, require refrigeration to store them and are associated with high rate of complications like nausea, vomiting, diarrhea and fever. ${ }^{6}$ Misoprostol have been in use for TOP in $2^{\text {nd }}$ trimester of pregnancy since 1990s. 
It is cost effective, easy to use, easy to store, no refrigeration required and minimum side effects reported. ${ }^{7,8}$

Misoprostol is used orally and vaginally. Vaginal route has been reported more effective in inducing abortion. According to a study rate of abortion via vaginal route is $90 \%$ as compared to oral route $69 \% .^{9}$ Few studies also recommend its use via sublingual route, with maximum efficacy. ${ }^{10}$ Misoprostol is stable at room temperature and is effective with or without mifepristone. Mifepristone is expensive and not available in some developing countries. ${ }^{11}$ Few studies reported that misoprostol in combination with mifepristone has great efficacy with short induction period. ${ }^{12}$ Previously many studies have been done on the use of misoprostol for TOP in first trimester, but there is very little data available regarding its efficacy in second trimester of pregnancy. Hence this study was conducted to determine efficacy of misoprostol when used alone via vaginal route in second trimester for termination of pregnancy.

\section{MATERIAL \& METHODS}

This cross sectional study was conducted at Obstetrics and Gynaecology Department, Jinnah Medical and Dental College, Karachi from March to August 2020. Pregnant ladies in second trimester of pregnancy admitted in Obstetrics and Gynecology department of Jinnah Medical and Dental College Karachi, in which medical termination of pregnancy was indicated for the sake of health issues of mothers like hypertension, diabetes mellitus or due to fetal death, missed abortion, congenital malformation of fetus, anencephaly or hydrocephalus with meningocele not likely to survive were included in this study. After taking proper history obstetrical examination was done. History of drug allergy was taken in detailed. Those cases in first or third trimester of pregnancy, or where surgical abortion was indicated, having abnormal placenta position, fetal macrosomia, or had previous uterine surgery now having scarred uterus, with multiple pregnancies or para-4 or more were excluded from the study. Cases were divided into two groups. Cases in group-A were given misoprostol 4 hourly, while those in group-B were given misoprostol 6 hourly. Misoprostol 200ug was given via vaginal route. Effect of the drug was monitored for 48 hours. Induction of abortion within 48 hours was labelled as effectiveness of the drug otherwise it was considered as failure of the drug. Cases were monitored for any complication of the drug like nausea, vomiting, fever or abdominal pain, tenderness denoting uterine rupture. Data collected was analyzed using SPSS-20. Sample size was calculated using $\mathrm{WHO}$ sample size calculator. Non-probability consecutive sampling technique was used for selection of study sample. Chi square test was applied on the data. Results were displayed in tabular and graphical form. Consent was taken from all women in study sample and ethical approval was also taken from ethical committee of the study hospital. (IRB0389)

\section{RESULTS}

Total 140 cases were included in the study, which were divided into two equal groups with 70 cases in each, Group-A and Group-B. Cases in group $A$ were given misoprostol 4 hourly for induction of abortion. Ae range of cases was 1640 years with mean age of $26.4 \pm 3.5$ years. Most of the cases were between 20 - 30 years of age. Abortion was induced in 66(94.3\%) cases while failure was reported in $4(5.7 \%)$ cases. Mean time for induction of labor was $12.3 \pm 2.7$ hours and mean gestational age was $19.52 \pm 4.6$ weeks in both group-A and group-B.

\begin{tabular}{|c|c|c|c|c|}
\hline \multirow{2}{*}{$\begin{array}{l}\text { Age } \\
\text { Groups }\end{array}$} & \multirow{2}{*}{$\begin{array}{c}\text { Total } \\
\text { Cases } \\
(\mathrm{N}=70)\end{array}$} & \multicolumn{2}{|c|}{$\begin{array}{c}\text { Abortion within } 48 \\
\text { hours }\end{array}$} & \multirow[t]{2}{*}{$\begin{array}{c}\text { P- } \\
\text { Value }\end{array}$} \\
\hline & & Yes & No & \\
\hline $16-20$ & $08(11.4 \%)$ & 08 (11.4\%) & $00(00 \%)$ & \multirow{6}{*}{0.413} \\
\hline $21-25$ & $20(28.6 \%)$ & 19 (27.1\%) & $01(1.4 \%)$ & \\
\hline $26-30$ & 25 (35.7\%) & 23 (32.8\%) & $02(2.8 \%)$ & \\
\hline $31-35$ & $12(17.1 \%)$ & $11(15.7 \%)$ & $01(1.4 \%)$ & \\
\hline$>35$ & 05 (7.1\%) & 05 (7.1\%) & $00(00 \%)$ & \\
\hline Total & 70 (100\%) & 66 (94.3\%) & 04 (5.7\%) & \\
\hline
\end{tabular}

Table-I. Efficacy of Misoprostol in Group-A relative to various age groups.

In Group-B 70 cases were included, mostly (37.1\%) between 26-30 years. Misoprostol was given 6 hourly to these cases via vaginal route. Successful abortion was reported in 58 (82.8\%) 
while failure reported in $12(17.1 \%)$ cases. Those showing drug failure were mostly between 20-30 years of age while cases with $<20$ years and $>30$ years of age showed good response.

\begin{tabular}{|c|c|c|c|c|}
\hline \multirow{2}{*}{$\begin{array}{l}\text { Age } \\
\text { Groups }\end{array}$} & \multirow{2}{*}{$\begin{array}{c}\text { Total } \\
\text { Cases } \\
(\mathrm{N}=70)\end{array}$} & \multicolumn{2}{|c|}{$\begin{array}{c}\text { Abortion within } 48 \\
\text { hours }\end{array}$} & \multirow{2}{*}{$\begin{array}{c}\text { P- } \\
\text { Value }\end{array}$} \\
\hline & & Yes & No & \\
\hline $16-20$ & 12 (17.1\%) & $10(14.3 \%)$ & 02 (2.8\%) & \multirow{6}{*}{0.426} \\
\hline $21-25$ & $18(25.7 \%)$ & 15 (21.4\%) & 03 (4.3\%) & \\
\hline $26-30$ & 26 (37.1\%) & 22 (31.4\%) & 04 (5.7\%) & \\
\hline $31-35$ & $10(14.3 \%)$ & $08(11.4 \%)$ & 02 (2.8\%) & \\
\hline$>35$ & $04(5.7 \%)$ & 03 (4.3\%) & 01 (1.4\%) & \\
\hline Total & 70 (100\%) & 58 (82.8\%) & $12(17.1 \%)$ & \\
\hline
\end{tabular}

Table-II Efficacy of Misoprostol in Group-B relative to various age groups.

In our study sample there were 59 (42.1\%) primigravida and 81 (57.9\%) multigravida cases. In group-A out of 33() primigravida misoprostol showed efficacy in 32() cases while failure reported in one case only. While out of 37 multigravida cases failure was reported in 03(8\%) cases.

\begin{tabular}{|c|c|c|c|c|}
\hline \multirow{2}{*}{$\begin{array}{c}\text { Gravida of } \\
\text { Women }\end{array}$} & $\begin{array}{c}|c| \\
\text { Efficacy of the }\end{array}$ & \multirow{2}{*}{$\begin{array}{c}\text { Total } \\
\text { drug within } \mathbf{4 8} \text { hrs }\end{array}$} & P-Value \\
\cline { 2 - 4 } & Yes & No & & \\
\hline Primigravida & $32(97 \%)$ & $01(3 \%)$ & 33 & 0.538 \\
\hline Multigravida & $34(92 \%)$ & $03(8 \%)$ & 37 & \\
\hline
\end{tabular}

In group-B out of 70 cases, 26(37.2\%) were primigravida and 44(62.8\%) were multigravida cases. In $88.5 \%$ primigravida and in $79.5 \%$ multigravida cases abortion happened while failure rate was $11.5 \%$ and $20.5 \%$ respectively in primgravida and multigravida cases in this group.

\begin{tabular}{|c|c|c|c|c|}
\hline $\begin{array}{c}\text { Gravida of } \\
\text { Women }\end{array}$ & \multicolumn{2}{|c|}{$\begin{array}{c}\text { Efficacy of the drug } \\
\text { within } \mathbf{4 8} \text { hrs }\end{array}$} & $\begin{array}{c}\text { Total } \\
\text { Cases }\end{array}$ & $\begin{array}{c}\text { P- } \\
\text { Value }\end{array}$ \\
\cline { 1 - 4 } & Yes & No & & \\
\hline Primigravida & $23(88.5 \%)$ & $03(11.5 \%)$ & 26 & 0.326 \\
\hline Multigravida & $35(79.5 \%)$ & $09(20.5 \%)$ & 44 & \\
\hline \\
Table-IV. Comparison of efficacy of the drug among \\
primigravida and multigravida in Group-B.
\end{tabular}

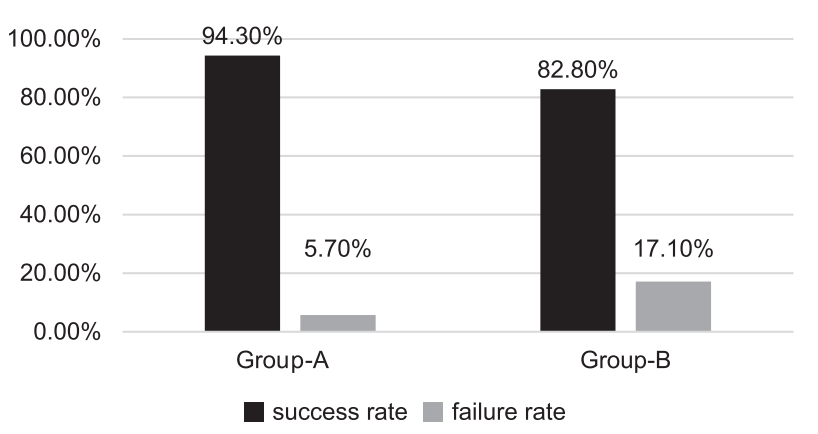

Figure-1. Comparison of misoprostol efficacy in both DISCUSSION Group-A and Group-B.

Misoprostol is an effective drug and safe while given trans-vaginally for inducing medical termination of pregnancy in second trimester of pregnancy. ${ }^{13}$ A study conducted in Nishtar Hospital Multan by Ashraf $S$ et al on efficacy of misoprostol given vaginally and judged within 72 hours of induction of labor. They reported success rate of $84.8 \%$ and failure rate of $15.1 \% .{ }^{14}$ These results are comparable to our study where we found success rate of $88.6 \%$ and failure rate of $11.4 \%$. Bansal et al reported mean induction time of labor $10.7 \pm 2.2$ hours after giving misoprostol vaginally. ${ }^{15}$ This is similar to mean induction time of $12.3 \pm 2.7$ hours in our study. In their study mean age of patients was $24.56 \pm 4.21$ years and mean gestational age was $17.21 \pm 3.22$ weeks. This is comparable to our study where mean age of patients was $26.4 \pm 3.5$ years and mean gestational age was $19.52 \pm 4.6$ weeks. A study conducted by Karande et al reported $100 \%$ success rate of intra vaginal misoprostol in second trimester. In their study primigravida were $23.3 \%$ and multigravida $76.7 \% .{ }^{16}$ In our study $42.1 \%$ were primigravida and $57.8 \%$ were multigravida women. This difference may be due to cultural and social differences as in our community mostly females marry in young age and due to unavailability of proper maternal healthcare services in periphery they experience many complications during first pregnancy and many times abortion is indicated due to negligence of mother and their caretakers. A similar study was conducted in India by Kusumam et al, they included $43.6 \%$ primigavida and $56.4 \%$ multigravida mothers, mean gestational age was 18.6 weeks, success rate was $78.3 \%$ and failure rate was $21.7 \%$ and mean induction abortion 
interval was 14.64 hours, similar to our study results. ${ }^{17}$ Previously a local study conducted in Bahawalpur (a city of Pakistan) reported success rate of $97.8 \%$ and failure rate of $2.2 \%$ among cases using misoprostol 4 hourly per vaginally, as compared to those using 6 hourly with success rate of $81.3 \%$ and failure rate of $18.7 \% .^{18}$

In early pregnancy failure misoprostol is used to evacuate uterus for dead fetus components. A study conducted in Netherland reported efficacy of misoprostol in complete evacuation rate of about $50 \%$ in such cases. ${ }^{19}$ In case of abortion If women do not evacuate spontaneously dead fetus immediately, medical or surgical methods are required for uterine evacuation. Surgical methods are associated with many complications, hence medical termination of pregnancy (TOP) is used. American College of Obstetricians and Gynecologists recommend medical method as safe, for TOP. ${ }^{20}$ In this study we used lower dose of misoprostol as compared to previous studies for TOP, and we observed good results. Misoprostol has dose related side effects, hence lowest effective dose causes minimum side effects. Previous literature is mostly about oral efficacy of misoprostol and very little data is present about its per-vaginal use, that's why more studies are required in this aspect.

\section{CONCLUSION}

Medical termination of pregnancy within 48 hours in second trimester using minimum effective dose of misoprostol $200 \mathrm{ug}$ given via vaginal route with 4 hourly intervals has been proved much effective with minimum side effects and low failure rate as compared to misoprostol given with 6 hourly intervals associated with relatively higher failure rate.

Copyright@ 25 Feb, 2021.

\section{REFERENCES}

1. Dawson AJ, Nicolls R, Bateson D, Doab A, Estoesta $\mathrm{J}$, Brassil A, et al. Medical termination of pregnancy in general practice in Australia: A descriptiveinterpretive qualitative study. Reprod Health. 2017; 14: 39.
2. Bello FA, Fawole B, Oluborode B, Awowole I, Irinyenikan T, Awonuga D, Loto O, Fabamwo A, Guest $P$, Ganatra $B$. Trends in misoprostol use and abortion complications: A cross-sectional study from nine referral hospitals in Nigeria. PloS one. 2018 Dec 31; 13(12):e0209415.

3. Grossman D, Baum SE, Andjelic D, Tatum C, Torres G, Fuentes L, Friedman J. A harm-reduction model of abortion counseling about misoprostol use in Peru with telephone and in-person follow-up: A cohort study. PLoS One. 2018 Jan 10; 13(1):e0189195.

4. Samnani AA, Rizvi N, Ali TS, Abrejo F. Barriers or gaps in implementation of misoprostol use for post-abortion care and post-partum hemorrhage prevention in developing countries: A systematic review. Reproductive health. 2017 Dec 1; 14(1):139.

5. Pourette D, Mattern C, Ratovoson R, Raharimalala P. Complications with use of misoprostol for abortion in Madagascar: between ease of access and lack of information. Contraception. 2018 Feb 1; 97(2):116-21.

6. Jelinska K, Yanow S. Putting abortion pills into women's hands: Realizing the full potential of medical abortion. Contraception. 2018 Feb 1; 97(2):869.

7. Baxerres C, Boko I, Konkobo A, Ouattara F, Guillaume A. Abortion in two francophone African countries: a study of whether women have begun to use misoprostol in Benin and Burkina Faso. Contraception. 2018 Feb 1; 97(2):130-6.

8. Kulczycki A. The imperative to expand provision, access and use of misoprostol for post-abortion care in sub-Saharan Africa. African journal of reproductive health. 2016; 20(3):22-5.

9. Moore AM, Philbin J, Ariawan I, Budiharsana M, Murro R, Aryanty RI, Bankole A. Online abortion drug sales in Indonesia: A quality of care assessment. Studies in Family Planning. 2020 Oct 20.

10. Løkeland M, Bjørge T, Iversen OE, Akerkar R, Bjørge $\mathrm{L}$. Implementing medical abortion with mifepristone and misoprostol in Norway 1998-2013. International journal of epidemiology. 2017 Apr 1; 46(2):643-51.

11. Kapp N, Eckersberger E, Lavelanet A, Rodriguez MI. Medical abortion in the late first trimester: A systematic review. Contraception. 2019 Feb 1; 99(2):77-86. 
12. Marwah S, Gupta S, Batra NP, Bhasin V, Sarna V, Kaur N. A comparative study to evaluate the efficacy of vaginal vs oral prostaglandin E1 analogue (Misoprostol) in management of first trimester missed abortion. Journal of clinical and diagnostic research: JCDR. 2016 May; 10(5):QC14.

13. Abdelshafy A, Awwad H, Abo-Gamra A, Alanwar A, Elkotb AM, Shahin M, Abd El-Razek M, Abbas AM. Sublingual vs vaginal misoprostol for completion of first trimester missed abortion: A randomised controlled trial. The European Journal of Contraception \& Reproductive Health Care. 2019 Mar 4; 24(2):134-9.

14. Ashraf S, Sahar A, Safdar S. Inducing abortion in 2nd trimester; efficacy of misoprostol with previous one cesarean section. Professional Medical Journal. 2017 Jun 1; 24(6). DOI:10.17957/TPMJ/17.3758.

15. Bansal R. A prospective comparative study of vaginal versus oral misoprostol only regimen for early second trimester pregnancy termination. International Journal of Medical Science and Diagnosis Research. 2019 Jan 30;3(1).

16. Karande SJ, Gunjotikar MS. Comparative study between intravaginal misoprostol and extra-amniotic instillation of ethacridine lactacte for second trimester abortion. International Journal of Reproduction, Contraception, Obstetrics and Gynecology.; 6(6):2576.
17. Kusumam VN, Khan NB, VG S. Comparison of effectiveness of mifepristone misoprostol combination versus mifepristone Foley EAS (Extraamniotic instillation of saline) combination in second trimester pregnancy termination. Indian Journal of Obstetrics and Gynecology Research. 2018 Dec 15; 5(4):530-4.

18. un Nisa S, Razaq F, un Nisa S. Comparison of efficacy of Misoprostol 4 hourly with Misoprostol 6 hour for Medical termination of pregnancy in second trimester. The Professional Medical Journal. 2020 Jan 10; 27(01):46-51. DOI: 10.29309/TPMJ/2020.27.1.3169.

19. van den Berg J, Hamel CC, Snijders MP, Coppus SF, Vandenbussche FP. Mifepristone and misoprostol versus misoprostol alone for uterine evacuation after early pregnancy failure: study protocol for a randomized double blinded placebo-controlled comparison (Triple M Trial). BMC pregnancy and childbirth. 2019 Dec; 19(1):1-8.

20. Rottenstreich A, Levin G, Shushan AB, Yagel S, Porat $S$. The role of repeat misoprostol dose in the management of early pregnancy failure. Archives of gynecology and obstetrics. 2019 Nov 1; 300(5):128793.

\begin{tabular}{|c|c|c|c|}
\hline \multicolumn{4}{|c|}{ AUTHORSHIP AND CONTRIBUTION DECLARATION } \\
\hline No. & Author(s) Full Name & Contribution to the paper & Author(s) Signature \\
\hline 1 & Komal Devi & Data analysis, Data collection. & \\
\hline 2 & Shazia Aftab & $\begin{array}{l}\text { Topic selection and data collection, } \\
\text { Abstract and recording. }\end{array}$ & \\
\hline 3 & Reena & $\begin{array}{l}\text { Data collection, Found additional } \\
\text { literature for information. }\end{array}$ & \\
\hline 4 & Huma Baloch & Data collection. & \\
\hline 5 & Devi Kumari & Data collection, Data analysis. & \\
\hline 6 & Samina Ayaz & $\begin{array}{l}\text { Data analysis, Drafting and } \\
\text { composisng. }\end{array}$ & Suminis \\
\hline
\end{tabular}

